\title{
Feeder Cattle Basis Risk and Determinants
}

\author{
Justin D. Bina ${ }^{\star}$ D, Ted C. Schroeder and Glynn T. Tonsor \\ Department of Agricultural Economics, Kansas State University, Manhattan, KS, USA \\ ${ }^{\star}$ Corresponding author: E-mail: justindbina@gmail.com
}

\begin{abstract}
The feeder cattle futures contract has been criticized in recent years as not providing an effective hedging instrument. Following historically volatile cattle markets in 2014-2015, feeder cattle basis risk escalated, fueling futures contract concerns. This study assesses these concerns, utilizing weekly auction data from 32 feeder cattle markets from 1992 to 2021. Examined for the first known time, feeder cattle market variation had a statistically and economically significant influence on basis risk. Basis variation differed across regions and marketing periods. Feeder cattle basis risk was historically high in 2014-2015 but declined to levels similar to 2011 by 2018.
\end{abstract}

Keywords: basis; CME Feeder Cattle Contract; price risk management; volatility

JEL classifications: Q02

\section{Introduction}

In the presence of notable market uncertainty, the CME Group Feeder Cattle Futures contract facilitates risk transfer from commercial users (hedgers) managing price risk to speculators seeking to profit from market volatility. The risk transfer function is a necessary component of any futures contract, and the performance and use of a contract determines its viability as a risk management tool. Dramatic price swings in U.S. cattle markets during 2014-2015 prompted concerns over the effectiveness of cattle futures contracts as hedging instruments (National Cattlemen's Beef Association, 2016; Schroeder, Tonsor, and Coffey, 2019). As a thinly traded contract relative to live cattle futures (Bina and Schroeder, 2019), concerns were exacerbated for feeder futures. Peel (2020) argued "Feeder futures have become increasingly volatile in ways that often appear unrelated to market fundamentals. Erratic futures price movements and increased basis volatility makes it difficult or impossible for the industry to use feeder futures for its two primary roles of risk management and price discovery."

This study determines whether feeder cattle basis risk has changed over time and identifies factors driving basis risk. In particular, we utilize hedonic modeling of weekly auction data from a comprehensive set of 32 feeder cattle markets. The models include feeder cattle futures price as a dependent variable, and we use these models to predict feeder cattle cash prices out of sample. Given the way our model is specified, out-of-sample price prediction errors represent unexplained cash price deviations from feeder cattle futures prices or other random variation. This prediction error serves as a direct measure of basis risk. We then estimate impacts of market conditions and cattle characteristics on out-of-sample price prediction errors to determine how basis risk has changed over time and varied with market fundamentals.

Previous literature on basis forecasting and basis risk has focused primarily on live cattle futures and has utilized aggregate price data (e.g., Coffey, Tonsor, and Schroeder, 2018;

(C) The Author(s), 2022. Published by Cambridge University Press on behalf of the Southern Agricultural Economics Association. This is an Open Access article, distributed under the terms of the Creative Commons Attribution licence (https://creativecommons.org/licenses/by/4.0/), which permits unrestricted re-use, distribution, and reproduction in any medium, provided the original work is properly cited. 
Garcia, Leuthold, and Sarhan, 1984; Leuthold, 1979; Liu et al., 1994; Parcell, Schroeder, and Dhuyvetter, 2000). Our study differs in that we implement comparatively more detailed weekly auction data in price predictions and use out-of-sample errors as a measure of feeder cattle basis risk. For heterogeneous feeder cattle, transaction price and associated basis varies on lot characteristics as well as market conditions at the time of sale. Aggregate basis forecasts and risk assessments cannot be expected to accurately portray cash-futures relationships for individual transactions possessing varying product traits. As such, using disaggregated data in this study allows for a more detailed assessment of basis risk across varying types of cattle and fundamental market characteristics than the aggregate data employed in previous literature. Basis variation impacts the effectiveness of feeder futures to transfer price risk. Thus, understanding how and why basis risk changes over time is essential for hedgers as well as for contract-design purposes. ${ }^{1}$ Results indicate feeder cattle market volatility had statistically and economically significant impacts on feeder cattle basis risk. In other words, when feeder cattle market risk was high, basis risk was also elevated. We further find basis risk varied across geographic location as well as seasonally. Overall basis risk increased dramatically during 2014-2015 relative to historical norms, but returned to levels similar to 2011 by 2018 .

\section{Previous Studies}

Futures contract success depends on predictability of basis, defined as cash price minus futures price. Unexpected basis variation reduces the ability of a futures contract to transfer risk, decreases access to alternative forward pricing mechanisms, and reduces overall use of the futures contract (Garcia and Sanders, 1996). Adverse unexpected basis changes result in financial losses, relative to expectations, to hedgers. Given the importance of basis on hedging effectiveness, previous literature has forecasted basis and analyzed basis determinants in a variety of ways.

Leuthold (1979) hypothesized live cattle basis reflected the expected change in cash price over time, caused by supply shifts. To test this, he regressed monthly live cattle basis against cattle supply factors approaching contract maturity. A large portion of basis variation for contracts 2-7 months from maturity could be explained by cattle supply factors including cattle slaughter, cattle on feed, corn price, feeder and fed steer prices, and seasonal variables. Tomek (1980) noted on Leuthold's work that live cattle futures prices for contracts 4-7 months from maturity had no relationship with current fed steer cash prices, but the relationship moved toward one-for-one as contract maturity date approached. This suggests live cattle spot and futures prices move independently for more distant futures contracts, but the two market prices move approximately one-to-one as futures maturity nears. Livestock is a nonstorable commodity that changes form over time. Thus, a disconnect between current cash prices and deferred contracts can be expected (Koontz, Hudson, and Hughes, 1992), though nearby basis should become more predictable as animals mature toward contract specifications.

Garcia, Leuthold, and Sarhan (1984) posited that basis for a nonstorable commodity is the difference between current cash price and expected future cash price and is a function of expected shifts in supply and demand. Using daily aggregate prices from several Midwest markets, they modeled live cattle and live hog basis variability as a function of the consumer price index, location, and time to maturity, among other factors. Basis risk was related to long-term price patterns and unexpected changes in price. Using monthly aggregate Kansas, Colorado, and Texas data to determine factors affecting live cattle basis, Parcell, Schroeder, and Dhuyvetter (2000) found corn price, market fundamentals, and seasonality were important basis determinants. Liu et al. (1994) focused on concerns of lack of convergence between cash and futures prices, employing monthly average price data to forecast live cattle basis during the month preceding contract delivery.

\footnotetext{
${ }^{1}$ Important to recognize is basis risk, though elevated at times, could still be less than cash market price risk, implying hedged risk could still be smaller than unhedged risk.
} 
Futures market variables such as open interest and the lagged spread between nearby and a 2-month deferred contract were statistically significant in explaining variation in live cattle basis, suggesting futures market information should be considered with supply and demand factors when forecasting nearby basis.

Following the feeder cattle futures contract change from physical delivery to cash settlement in 1986, Kenyon, Bainbridge, and Ernst (1991) analyzed the effect of cash settlement on basis variability and predictability. Implementing weekly average price data for Oklahoma City and Southwest Virginia markets, standard deviations of feeder steer basis declined 3\%-14\% after cash settlement was introduced, but results were not statistically significant. Further, transaction data for 16 Virginia markets were used to estimate basis as a function of lot characteristics and futures contract month and to forecast basis before and after implementation of cash settlement. In general, basis forecast errors for individual lots did not change under cash settlement, suggesting basis risk did not change for feeder cattle hedgers under the new contract specifications.

Assessing feeder cattle basis levels across key production states, Seamon, Sullivan, and Umubyeyi (2019) found statistically significant differences in basis across Nebraska, Kansas, and Texas. Kansas and Texas, but not Nebraska, exhibited statistically significant seasonality in feeder cattle basis. Though seasonal patterns in feeder cattle basis can be accounted for in some markets, unexpected basis fluctuations reduce hedging performance. An analysis of market fundamentals and price momentum on live cattle hedging by Coffey, Tonsor, and Schroeder (2018) found the impacts of market factors (such as aggregate supply of cattle, cattle market weights, and delivery costs) and price trends on basis prediction errors varied across regions. For example, Kansas and Texas exhibited weaker than expected basis when heavier than average cattle were being marketed. However, the results were not consistent across cattle feeding regions. The diversity of cattle markets and basis predictability across regions highlighted the need for cattle producers to understand local market conditions. Doing so necessitates detailed basis risk assessments addressed in this study.

\section{Procedure and Data}

A multistep procedure was used to assess basis risk. First, hedonic models were estimated using 5 years of weekly auction data (and rolled forward yearly) to predict prices for individual observations during the subsequent year in an out-of-sample fashion. Second, out-of-sample prediction errors, interpreted as out-of-sample basis risk for reported feeder cattle sale observations, were calculated for all observations across each out-of-sample year. Third, the mean absolute values of out-of-sample prediction errors were used to quantify basis variation across cattle types and market locations. ${ }^{2}$ Fourth, out-of-sample basis variation was regressed against market conditions to quantify factors associated with basis risk.

\subsection{Data}

Weekly auction data for all grades of feeder steers and heifers ranging in average weight from 450 to 849 pounds were obtained from the U.S. Department of Agriculture Agricultural Marketing Service (AMS) Weighted Average Reports for 32 auction market locations. These reports summarize weekly feeder cattle auction transactions, aggregating lots sold by sex, frame size, and muscle thickness (e.g., Medium and Large \#1-2), 50-pound weight groupings, and cattle sold with quality-related comments. Mitchell, Peel, and Brorsen (2018) used similar AMS data in hedonic modeling of Oklahoma cow auction prices. An estimated 39\% of the individual report

\footnotetext{
${ }^{2}$ Risk is not evaluated from a short or long hedging perspective, which necessitates a directional measure of basis risk. This study focuses on overall basis variation present and, as such, employs mean absolute errors to measure basis risk.
} 


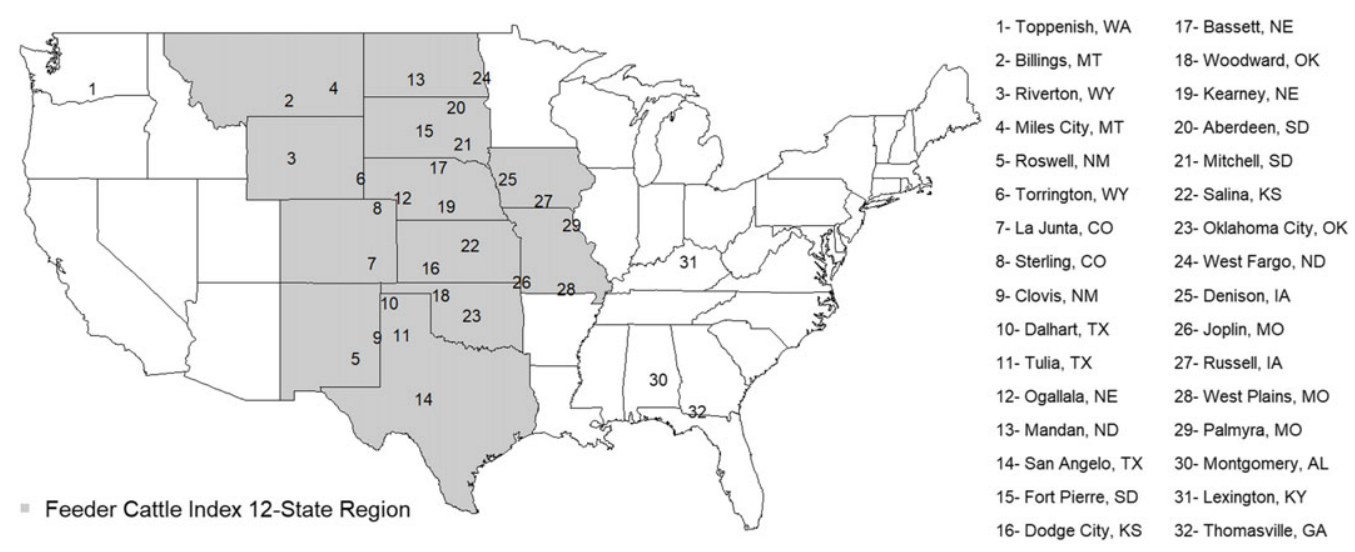

Figure 1. Selected feeder cattle market locations used to evaluate basis risk.

entries in our feeder cattle data set represent a single lot, or individual transaction, and in other cases represent an aggregation of multiple similar lots. ${ }^{3}$

Cattle identified by an AMS market reporter as having a differentiating characteristic are "commented" in market reports. Comments on cattle are generally associated with either a quality or condition price premium or discount. Commented lots are treated as unique observations in the AMS reports and are reported separately from other feeder cattle sale observations having similar sex, weight, and grade.

Figure 1 depicts the selected market locations. Auction market data go through December 7 , 2021; however, the earliest available data vary by market (summarized in Table 1). Twenty-eight of the markets analyzed reside within the CME Feeder Cattle Index 12-State Region and were chosen as they are high-volume feeder cattle markets and provide geographic dispersion. Toppenish, WA (Pacific Northwest), and Montgomery, AL, Lexington, KY, and Thomasville, GA (Southeast) were selected to evaluate basis risk in higher-volume markets outside of the 12-State Region.

To reduce impacts of data errors and abnormal transactions, cash prices were calculated as a percentage of the same day's nearby feeder futures settlement price. Then, separately for each market and sex, observations were omitted where cash price (as a percentage of nearby feeder cattle futures price) was outside the range of \pm 2.5 median absolute deviations from the median to remove outliers (Leys et al., 2013). This procedure resulted in 917,732 observations available for analysis (of 957,741 original observations). ${ }^{4}$

Daily settlement prices for the nearby CME Group feeder cattle and corn futures contracts were obtained from Bloomberg (2020a). The nearby futures price was defined as the settlement price of the nearest available contract up to contract expiration, at which point the nearby price rolled forward to the next available contract month. Daily put and call implied volatilities (IV) for nearby at-the-money corn options were likewise obtained (Bloomberg, 2020b). An average of the call and put IV was calculated to obtain a single daily IV value. If a call (put) IV was missing, the put (call) IV was used as the daily IV value. Monthly average IV were calculated from the daily values.

\footnotetext{
${ }^{3}$ Report entries where the price spread was zero were assumed to be individual transactions.

${ }^{4}$ Key conclusions remained robust to multiple methods of filtering feeder cattle observations. Alternative methods analyzed included (1) omitting observations where cash price (as a percentage of nearby futures price) was in the top or bottom $1 \%$ of observations, (2) omitting observations where cash price (as a percentage of nearby futures price) was outside the range of \pm 3 standard deviations from the mean, and (3) using no filtering method.
} 
Table 1. Summary of selected feeder cattle markets analyzed

\begin{tabular}{|c|c|c|c|}
\hline Market & First Year of Data & Observations & Number of Auction Dates \\
\hline [Montgomery, AL] & 2005 & 15,859 & 700 \\
\hline La Junta, CO & 1994 & 17,570 & 1,026 \\
\hline Sterling, CO & 2003 & 10,751 & 421 \\
\hline [Thomasville, GA] & 2003 & 9,367 & 731 \\
\hline Denison, IA & 1998 & 15,260 & 629 \\
\hline Russell, IA & 1995 & 15,596 & 587 \\
\hline Dodge City, KS & 1995 & 39,600 & 1,340 \\
\hline Salina, KS & 1995 & 45,702 & 1,288 \\
\hline [Lexington, KY] & 2009 & 26,822 & 913 \\
\hline Joplin, MO & 1996 & 67,542 & 1,344 \\
\hline Palmyra, MO & 1996 & 21,143 & 1,091 \\
\hline West Plains, MO & 1996 & 65,821 & 1,250 \\
\hline Billings, MT & 1994 & 22,129 & 1,382 \\
\hline Miles City, MT & 2008 & 9,615 & 516 \\
\hline Mandan, ND & 1998 & 15,928 & 697 \\
\hline West Fargo, ND & 1995 & 13,986 & 505 \\
\hline Bassett, NE & 1999 & 11,430 & 547 \\
\hline Kearney, NE & 1994 & 25,397 & 1,076 \\
\hline Ogallala, NE & 1999 & 11,553 & 568 \\
\hline Clovis, NM & 1995 & 44,928 & 1,219 \\
\hline Roswell, NM & 1995 & 34,348 & 1,187 \\
\hline Oklahoma City, OK & 1994 & 85,536 & 1,360 \\
\hline Woodward, OK & 1994 & 44,440 & 1,352 \\
\hline Aberdeen, SD & 2003 & 20,037 & 890 \\
\hline Fort Pierre, SD & 1996 & 19,694 & 893 \\
\hline Mitchell, SD & 1997 & 23,065 & 851 \\
\hline Dalhart, TX & 1992 & 40,253 & 1,410 \\
\hline San Angelo, TX & 1994 & 40,954 & 1,430 \\
\hline Tulia, TX & 2001 & 30,854 & 1,000 \\
\hline [Toppenish, WA] & 1995 & 21,337 & 1,312 \\
\hline Riverton, WY & 1995 & 13,214 & 1,071 \\
\hline Torrington, WY & 1995 & 22,984 & 1,644 \\
\hline
\end{tabular}

Note: [ ] Denotes a market outside of the Feeder Cattle Index 12-State Region.

\subsection{Hedonic Models}

Past studies on basis forecasting methods and hedging cattle have implemented historical average basis values to analyze out-of-sample basis prediction errors (e.g., Coffey, Tonsor, and Schroeder, 2018; Tonsor, Dhuyvetter, and Mintert, 2004). Coffey, Tonsor, and Schroeder (2018) state 
expected basis is a better predictor if current supply and demand factors are similar to those when the basis prediction was made. Any method of predicting basis will be more accurate if these factors remain similar year-to-year. Additionally, Tonsor, Dhuyvetter, and Mintert (2004) suggested incorporating current information into basis forecasts to improve basis forecasting accuracy. However, their analysis was constrained to a single feeder cattle cash price series, chosen to hold hedge ratios near 1.0 over the selected time series. Because feeder cattle prices and associated basis vary substantially across cattle characteristics and market conditions, we extend previous work in a more detailed fashion. In particular, we use hedonic modeling of feeder cattle auction data as it allows for an in-depth basis risk analysis across a broader set of cattle types, locations, and market conditions than previous work. By controlling for transaction characteristics, this method results in more informed basis models than traditional time series models using aggregate data.

Our hedonic model includes feeder cattle futures price on the right-hand side, and, as such, prediction errors are the variation in cash price unexplained by feeder cattle futures and other model variables. This unexplained variation in feeder cattle cash price provides a measure of basis risk. Hedonic modeling and detailed feeder cattle auction data allow us to measure basis risk for each observation across numerous cofactors including auction location, year, season, animal sex, weight category, lot size, grade, comments, and varying feed costs, providing a more thorough basis risk assessment than previous studies.

Hedonic pricing models were estimated separately by sex (steer or heifer) and market location for 5-year rolling samples of weekly auction data. Using the coefficients from these models, out-of-sample feeder cattle price predictions were made for the subsequent year. Thus, each observation had an out-of-sample predicted price dependent on (1) observationspecific sex and market location hedonic pricing model coefficients from the previous 5 years and (2) cattle characteristics and market conditions on the day the cattle were sold.

The hedonic pricing model employed is as follows:

$$
\begin{aligned}
\text { PRICE }_{i t}= & b_{0}+b_{1} \mathrm{FF}_{t}+b_{2} \frac{\mathrm{FF}_{t}}{\mathrm{WT}_{i t}}+b_{3} \frac{\mathrm{FF}_{t}}{\mathrm{WTSQ}_{i t}}+b_{4} \frac{\mathrm{FF}_{t}}{\mathrm{CF}_{t}}+b_{5} \frac{\mathrm{FF}_{t}}{\mathrm{CF}_{t}} \mathrm{FIVE}_{i t}+b_{6} \frac{\mathrm{FF}_{t}}{\mathrm{CF}_{t}} \mathrm{SIX}_{i t} \\
& +b_{7} \frac{\mathrm{FF}_{t}}{\mathrm{CF}_{t}} \mathrm{SEVEN}_{i t}+b_{8} \mathrm{HD}_{i t}+b_{9} \mathrm{HDSQ}_{i t}+\sum_{m=1}^{11} b_{m+9} \mathrm{MONTH}_{m t} \\
& +\sum_{g=1}^{34} b_{g+20} \mathrm{GRADE}_{i g t}+b_{55} \mathrm{COMMPREM}_{i t}+b_{56} \mathrm{COMMDISC}_{i t}+e_{i t}
\end{aligned}
$$

where $\mathrm{PRICE}_{i t}$ is the weighted average cash price for observation $i$ during auction date $t$, and $e$ is an error term (variable definitions are provided in Table 2). Hedonic models were estimated using weighted least squares (weighted by number of head) to account for differing number of feeder cattle included in each observation.

Nearby feeder cattle futures prices (FF) are included to account for the effect of futures price on cash price (Schroeder et al., 1988), making the random error term reflect basis risk. Average cattle weight in each observation is included to account for changing cash price per pound across animal weight (e.g., Kenyon, Bainbridge, and Ernst, 1991; Schroeder et al., 1988; Zimmerman et al., 2012). Price is expected to decrease at a decreasing rate as animal weight increases. Weight (WT) and weight-squared (WTSQ) are made inverse variables to account for the nonlinear relationship between feeder cattle price and animal weight and to guarantee a downward-sloping relationship at heavier weights. In addition, feeder futures price impact on cash price is conditional on animal weight because lighter-weight cattle prices vary more with futures prices compared to price of cattle meeting futures contract weight specifications. As such, weight and weight-squared variables are interacted with feeder futures.

Nearby corn futures prices are expected to influence the feeder cattle weight-price slide (Dhuyvetter and Schroeder, 2000). When corn price (and associated cost of gain) decreases, cash 
Table 2. Description of variables used in hedonic pricing models

\begin{tabular}{|c|c|c|}
\hline Characteristic & Description & Variable Name \\
\hline Price $(\$ / c w t)$ & Feeder cattle weighted average cash price & PRICE \\
\hline Feeder futures (\$/cwt) & Nearby feeder cattle futures settlement price & FF \\
\hline \multirow[t]{2}{*}{ Weight (lb.) } & Average weight per animal & WT \\
\hline & Average weight per animal squared & WTSQ \\
\hline Corn futures (cents/bu.) & Nearby corn futures settlement price & $C F$ \\
\hline \multirow[t]{4}{*}{ Weight $(0,1)$} & $=1$ if $450 \mathrm{lb} . \leq$ average weight per animal $<550 \mathrm{lb} . ;=0$ otherwise & FIVE \\
\hline & $=1$ if $550 \mathrm{lb} . \leq$ average weight per animal $<650 \mathrm{lb} . ;=0$ otherwise & $S I X$ \\
\hline & $=1$ if $650 \mathrm{lb} . \leq$ average weight per animal $<750 \mathrm{lb} . ;=0$ otherwise & SEVEN \\
\hline & $750 \mathrm{lb} . \leq$ average weight per animal $<850 \mathrm{lb}$. (default) & EIGHT \\
\hline \multirow[t]{2}{*}{ Headcount (head) } & Number of head & $H D$ \\
\hline & Number of head squared & HDSQ \\
\hline Month $(0,1)$ & Month sold (January default) & MONTH \\
\hline Grade $(0,1)$ & Frame size and thickness (Medium \& Large \#1-2 default) & GRADE \\
\hline \multirow[t]{2}{*}{ Comments $(0,1)$} & $\begin{array}{l}=1 \text { if commented as fancy, gaunt, thin fleshed, or value added; } \\
=0 \text { otherwise }\end{array}$ & COMMPREM \\
\hline & $\begin{array}{l}=1 \text { if commented as Brahman cross, fleshy, full, or unweaned; } \\
=0 \text { otherwise }\end{array}$ & COMMDISC \\
\hline
\end{tabular}

price of lighter-weight cattle increases, making lighter cattle more valuable per pound than heavier cattle. Further, corn price may influence how feeder cattle futures prices affect cash prices and this influence could vary by animal weight. For instance, when corn price is high, price of lighterweight cattle will be more responsive to changes in feeder cattle futures prices compared to cattle meeting futures contract weight specifications. Previous work in live cattle basis modeling (e.g., Leuthold, 1979; Parcell, Schroeder, and Dhuyvetter, 2000) has included the price of corn. To account for the influence of corn price on cash feeder price and the futures-cash relationship, nearby corn futures price (CF) is included as an inverse variable and is interacted with feeder futures and categorical weight (FIVE, SIX, and SEVEN). Interacting numerous variables with continuous cattle weight variables resulted in collinearity and unstable parameter estimates, necessitating interactions of corn price with categorical, rather than continuous, weight variables.

Additional feeder cattle lot information such as lot size and its square, frame size, muscle score, condition, and fill have been used in past literature (e.g., Kenyon, Bainbridge, and Ernst, 1991; Schroeder et al., 1988; Zimmerman et al., 2012) modeling feeder cattle price and basis. Nonlinear cash price effects of the number of head sold are captured by including headcount (HD) and headcount squared (HDSQ). Categorical variables for month sold (MONTH), grade (GRADE), and commented cattle capture price effects of observation-specific characteristics. ${ }^{5}$ Separate categorical variables were created for comments typically associated with a premium (COMMPREM) and comments typically associated with a discount (COMMDISC). Table 3 provides descriptive statistics of data used in the hedonic models. Observations from 2021 are not included in Table 3 as 2021 data were not included in hedonic models (i.e., a 2016-2020 model was the last 5-year rolling sample).

\footnotetext{
${ }^{5}$ Categorical grade variables are created for all combinations of feeder cattle frame size (Small, Medium, and Large) and thickness (\#1-4), and for mixtures of frame size and/or thickness (e.g., Medium \& Large \#2-3). The occurrence of each grade variable varies across hedonic models.
} 
Table 3. Descriptive statistics of variables used in hedonic pricing models, 1992-2020

\begin{tabular}{|c|c|c|c|c|c|}
\hline & Mean & Median & SD & Minimum & Maximum \\
\hline \multicolumn{6}{|l|}{ Dependent Variable } \\
\hline Price $(\$ / c w t)$-Steers & 123.07 & 116.00 & 41.14 & 38.50 & 335.86 \\
\hline Price $(\$ / c w t) —$ Heifers & 113.45 & 107.82 & 37.12 & 36.00 & 300.94 \\
\hline \multicolumn{6}{|l|}{ Continuous Variables } \\
\hline Feeder futures (\$/cwt) & 111.71 & 103.68 & 37.80 & 48.08 & 242.33 \\
\hline Corn futures (cents/bu.) & 344.52 & 327.50 & 140.21 & 174.75 & 831.25 \\
\hline Weight (lb.) & 634.81 & 626.67 & 106.35 & 450.00 & 849.00 \\
\hline Headcount (head) & 59.59 & 24.00 & 96.84 & 1 & 5,000 \\
\hline Categorical Variables & \multicolumn{2}{|c|}{$\%$ of Obs } & & & \\
\hline 450-549 lb. & \multicolumn{2}{|c|}{26.01} & & & \\
\hline 550-649 lb. & \multicolumn{2}{|c|}{30.02} & & & \\
\hline 650-749 lb. & \multicolumn{2}{|c|}{25.83} & & & \\
\hline $750-849 \mathrm{lb}$. & \multicolumn{2}{|c|}{18.15} & & & \\
\hline Comments-Premium & \multicolumn{2}{|c|}{5.22} & & & \\
\hline Comments-Discount & \multicolumn{2}{|c|}{6.86} & & & \\
\hline
\end{tabular}

Note: Observations (Steers) $=449,675$; Observations (Heifers) $=417,131$; Number of Auction Dates $=6,839$.

\subsection{Mean Absolute Errors}

Out-of-sample price predictions, or basis risk, derived from the hedonic pricing models are used to compute mean absolute errors (MAE), expressed as:

$$
\text { MAE }=\frac{1}{n} \sum_{i=1}^{n} \mid \text { PRICE }_{i t}-\text { PREDICTION }_{i t} \mid
$$

where $n$ is the number of observations for each market location $(l)$, for each sex $(s)$, during each month $(m)$, for each weight class $(w)$. For notational convenience, subscripts for location, sex, month, and weight class are omitted in equation (2). PREDICTION is each observation's unique out-of-sample predicted price and the term inside the absolute value bracket is the out-of-sample basis risk value or the difference of each predicted price from the actual cash price. MAE is calculated separately by location $(l)$, sex $(s)$, month $(m)$, and weight class $(w)$, providing a single value of basis risk for feeder cattle with comparable traits. ${ }^{6}$

\subsection{Explaining MAE}

To evaluate how basis risk has changed over time and determine factors associated with those changes, we regress MAE values calculated from equation (2) against selected variables. The model is:

\footnotetext{
${ }^{6}$ Producers may hedge numerous transactions, with each resulting in gains or losses from basis risk. Some portion of these basis risk impacts may offset and, as such, mean absolute errors potentially overstate basis risk for these producers.
} 


$$
\begin{aligned}
\operatorname{MAE}_{l s m w}= & b_{0}+b_{1} \mathrm{AVGFF}_{m}+b_{2} \mathrm{AVGCF}_{m}+b_{3} \mathrm{FHV}_{m}+b_{4} \mathrm{AVGCIV}_{m} \\
& +\sum_{l=1}^{31} b_{4+l} \mathrm{LOCATION}_{l}+\sum_{y=1}^{21} b_{35+y} \mathrm{YEAR}_{y}+\sum_{m=1}^{11} b_{56+m} \mathrm{MONTH}_{m} \\
& +b_{68} \mathrm{FIVE}_{w}+b_{69} \mathrm{SIX}_{w}+b_{70} \operatorname{SEVEN}_{w}+e_{l s m w}
\end{aligned}
$$

Monthly average feeder cattle (AVGFF) and corn futures prices (AVGCF) are included to determine how changes in market prices impact feeder cattle basis risk (out-of-sample MAE). Coffey, Tonsor, and Schroeder (2018) similarly used live steer and corn prices to capture current market conditions in modeling live cattle basis prediction errors. Monthly feeder cattle historical volatility (FHV) and monthly average nearby corn implied volatility (AVGCIV) are included to evaluate effects of market variation on basis risk. ${ }^{7}$ Intuitively, greater uncertainty in feeder cattle and corn markets would make it more difficult to predict feeder cattle basis. We are aware of no prior research that has quantified these impacts. Feeder cattle historical volatility was used instead of option implied volatility (as used for corn) to avoid simultaneity with feeder basis risk and because thinly traded feeder cattle option contracts may make implied volatility unreliable. Implied volatility of an option contract is the market's forecast of future volatility in the underlying asset price (Canina and Figlewski, 1993). In this instance, implied volatility is the market's expectation of future volatility in corn futures priced into option premiums.

Categorical variables are included for market location (LOCATION) to determine how basis risk varies across geographic locations. Categorical year variables (YEAR) are included to evaluate how feeder cattle basis risk has changed over time and to account for changes in contract weight specifications that may have impacted basis risk (e.g., January 2000, January 2005, August 2005, and November 2016 contracts). Categorical month (MONTH) variables allow for seasonality in basis risk. Lastly, categorical weight variables (FIVE, SIX, and SEVEN) are included to measure basis risk across animal weight. Table 4 further describes variables utilized in equation (3) while Table 5 provides descriptive statistics.

\section{Results}

\subsection{Hedonic Pricing Models}

Hedonic pricing models were estimated to predict out-of-sample prices for feeder cattle with varying characteristics and market conditions at time of sale, providing a measure of basis risk for each observation. The hedonic framework depicted in equation (1) was applied to each market location and sex and for 5 years of weekly auction data subsequently rolling forward by adding a new year of data and dropping the oldest year. The number of hedonic pricing models estimated for each market location depended on data availability. For example, the first year of available data for Salina, KS, was 1995. Hedonic models for Salina steers and heifers were estimated for time periods of 1995-1999, 1996-2000 ... 2016-2020. A total of 1,250 hedonic models were estimated. Adjusted $R$-squared values ranged from 0.69 (2006-2010 Roswell heifer model) to 0.99 (2010-2014 Fort Pierre steer model) with a mean of 0.92 and median of 0.94 .

Feeder cattle futures coefficients were, as expected, positive and statistically significant ( 0.05 level) for $92 \%$ of the estimated hedonic models. Expectations of the effect of weight on feeder cattle price are generally held based on coefficients for the feeder futures to weight ratio and feeder futures to weight-squared ratio. For $80 \%$ of models, lighter-weight animals experienced higher prices, with price decreasing at a decreasing rate with increasing animal weight. Increases in the feeder cattle-to-corn futures ratio result from either increases in feeder futures price or decreases in corn futures price, both of which we expect to result in increased feeder cattle cash prices. As such, we expect a positive relationship between this variable and cash price.

\footnotetext{
${ }^{7}$ Nearby implied volatility is the weighted average of the volatilities of the two call (put) options closest to the at-the-money strike price and for the nearest contract expiration that is at least 20 days out.
} 
Table 4. Description of variables used in MAE models

\begin{tabular}{|c|c|c|}
\hline Characteristic & Description & Variable Name \\
\hline Mean absolute error $(\$ / c w t)$ & $\begin{array}{l}\text { Mean absolute error of out-of-sample predicted feeder cattle } \\
\text { cash prices }\end{array}$ & MAE \\
\hline Average feeder futures $(\$ / c w t)$ & $\begin{array}{l}\text { Monthly average nearby feeder cattle futures settlement } \\
\text { prices }\end{array}$ & AVGFF \\
\hline Average corn futures (cents/bu.) & Monthly average nearby corn futures settlement prices & AVGCF \\
\hline $\begin{array}{l}\text { Feeder cattle historical volatility } \\
(\$ / \text { cwt })\end{array}$ & $\begin{array}{l}\text { Monthly standard deviation of nearby feeder cattle futures } \\
\text { settlement prices }\end{array}$ & FHV \\
\hline $\begin{array}{l}\text { Average corn implied volatility } \\
\text { (annualized \%) }\end{array}$ & $\begin{array}{l}\text { Monthly average nearby implied volatility of at-the-money } \\
\text { corn options (average of call and put IVs) }\end{array}$ & AVGCIV \\
\hline Market location $(0,1)$ & Market location (Oklahoma City default) & LOCATION \\
\hline Year $(0,1)$ & Year sold (2021 default) & YEAR \\
\hline Month $(0,1)$ & Month sold (January default) & MONTH \\
\hline \multirow[t]{4}{*}{ Weight $(0,1)$} & $450 \mathrm{lb} . \leq$ average weight per animal $<550 \mathrm{lb}$. & FIVE \\
\hline & $550 \mathrm{lb} . \leq$ average weight per animal $<650 \mathrm{lb}$ & $S I X$ \\
\hline & $650 \mathrm{lb} . \leq$ average weight per animal $<750 \mathrm{lb}$. & SEVEN \\
\hline & $\begin{array}{l}750 \mathrm{lb} . \leq \text { average weight per animal }<850 \mathrm{lb} . \\
\text { (default) }\end{array}$ & EIGHT \\
\hline
\end{tabular}

Table 5. Descriptive statistics of variables used in MAE models, 1997-2021

\begin{tabular}{|c|c|c|c|c|c|}
\hline & Mean & Median & SD & Minimum & Maximum \\
\hline \multicolumn{6}{|l|}{ Dependent Variable } \\
\hline Mean absolute error $(\$ / c w t)$-Steers & 17.06 & 13.70 & 12.34 & 0.041 & 124.02 \\
\hline Mean absolute error $(\$ / c w t)$ —Heifers & 14.26 & 11.29 & 10.91 & 0.047 & 107.95 \\
\hline \multicolumn{6}{|l|}{ Continuous Variables } \\
\hline Average feeder futures $(\$ / c w t)$ & 120.22 & 112.95 & 36.86 & 67.80 & 239.52 \\
\hline Average corn futures (cents/bu.) & 367.27 & 358.10 & 151.19 & 178.29 & 803.54 \\
\hline Feeder cattle historical volatility (\$/cwt) & 1.98 & 1.57 & 1.35 & 0.36 & 9.14 \\
\hline Average corn implied volatility (annualized \%) & 26.46 & 24.88 & 7.81 & 11.31 & 48.61 \\
\hline
\end{tabular}

Note: Observations (Steers) $=27,832$; Observations (Heifers) $=27,749$.

Our expectation was generally met, as $53 \%$ of models exhibited a positive and statistically significant coefficient for the feeder to corn futures ratio. Interactions of the feeder to corn futures ratio with 450-549 pound, 550-649 pound, and 650-749 pound categorical weights were positive and statistically significant for $37 \%, 32 \%$, and $23 \%$ of models, respectively, meaning that lighter-weight cattle more often had statistically different feeder futures-to-corn futures ratio coefficients than the default 750-849 pound animal. The impact of the feeder-corn futures ratio on cash price was generally greater for lighter-weight cattle. For $64 \%$ of models, the magnitude of the categorical weight interaction term coefficient decreased as categorical weight increased.

Expectations of the effect of headcount on feeder cattle price generally held based on coefficients for headcount and headcount squared. Larger headcounts realized higher prices at a declining rate for $55 \%$ of hedonic models. Monthly binary variables revealed statistically 
significant seasonality in the majority of models. Also, commented cattle generally received statistically significant premiums or discounts.

\subsection{Basis Variation}

Using out-of-sample price prediction errors (basis risk), MAE were calculated for each location, sex, month, and weight class. ${ }^{8}$ Equation (3) was then estimated separately for steers and heifers to determine the impact of market conditions and feeder cattle characteristics on MAE values. Results are reported in Table A1. The models explained $43 \%$ of the variability in MAE.

Monthly average feeder cattle futures had a negative and statistically significant ( 0.05 level) impact on MAE for both steers and heifers. A $\$ 1$ per hundredweight increase in feeder futures resulted in a $\$ 0.05$ per hundredweight decrease in feeder steer MAE and a $\$ 0.10$ per hundredweight decrease in feeder heifer MAE. Though previous literature had not used futures prices as a right-hand-side variable in estimating feeder cattle basis risk, Garcia, Leuthold, and Sarhan (1984) found a positive and statistically significant (0.05 level) impact of the consumer price index on live cattle basis risk for December and June contracts, indicating higher overall prices result in higher basis risk. Monthly average corn futures had a negative and statistically significant (0.05 level) impact on MAE for both steer and heifer models. A 1 cent per bushel increase in corn futures resulted in slightly less than a $\$ 0.01$ per hundredweight decrease in MAE for both sexes. Previous literature on basis had not implemented corn futures as an independent variable in estimating feeder cattle basis risk. However, Leuthold (1979) found an inverse relationship between corn price and live cattle basis for a nearby contract, with a $\$ 1$ per bushel increase in corn price lowering basis by $\$ 1.33$ per hundredweight. Similarly, Parcell, Schroeder, and Dhuyvetter (2000) found a $\$ 1$ per bushel increase in the nearby corn futures price resulted in $\$ 0.75, \$ 0.82$, and $\$ 0.90$ per hundredweight declines in live cattle basis for Colorado, Kansas, and Texas, respectively.

Monthly feeder cattle futures historical volatility had a positive and statistically significant (0.05 level) impact on feeder steer and heifer MAE. A \$1 per hundredweight increase in feeder cattle historical volatility was associated with a $\$ 0.62(\$ 0.54)$ per hundredweight increase in steer (heifer) MAE. Monthly average corn implied volatility had a small, negative impact on both feeder steer and heifer MAE, but was not statistically significant ( 0.05 level) in either model. This is the first study we are aware of directly estimating the impact of volatility in derivatives markets on feeder cattle basis risk.

The impact and statistical significance of categorical location variables on MAE values varied. ${ }^{9}$ Relative to Oklahoma City, steer MAEs were not statistically different ( 0.05 level) in the Oklahoma Panhandle and Southeast Kansas. Other markets within the Index 12-State Region and into the Pacific Northwest experienced \$1-\$6 per hundredweight higher steer MAE. Out-of-Index markets to the east (i.e., Lexington and Montgomery) experienced lower steer MAE. For heifers, MAE was generally not statistically different ( 0.05 level) than Oklahoma City in the southern and western portions of the 12-State Region. Heifer MAE was statistically higher in many northern markets and in the out-of-Index markets, Montgomery and Toppenish.

All categorical year coefficients were statistically different ( 0.05 level) than the default 2021 , with the exception of 2012 for the heifer model. Feeder steer and heifer MAEs gradually increased from 1997 to 2013, elevated sharply to around \$16-\$22 per hundredweight over the default 2021 in 2014-2015, and then declined post-2015 (Figure 2). MAE for both sex returned to levels

\footnotetext{
${ }^{8} \mathrm{An}$ alternative measure of basis risk, root mean squared error, was also evaluated and results provided the same conclusions.

${ }^{9}$ Certain markets (e.g., Miles City, Aberdeen, and Montgomery) exhibit notable differences in categorical location coefficients between steers and heifers. Limited observations (see Table 1) in out-of-sample periods for these markets (with available years being some of the most volatile) make interpretation of location effects less certain.
} 


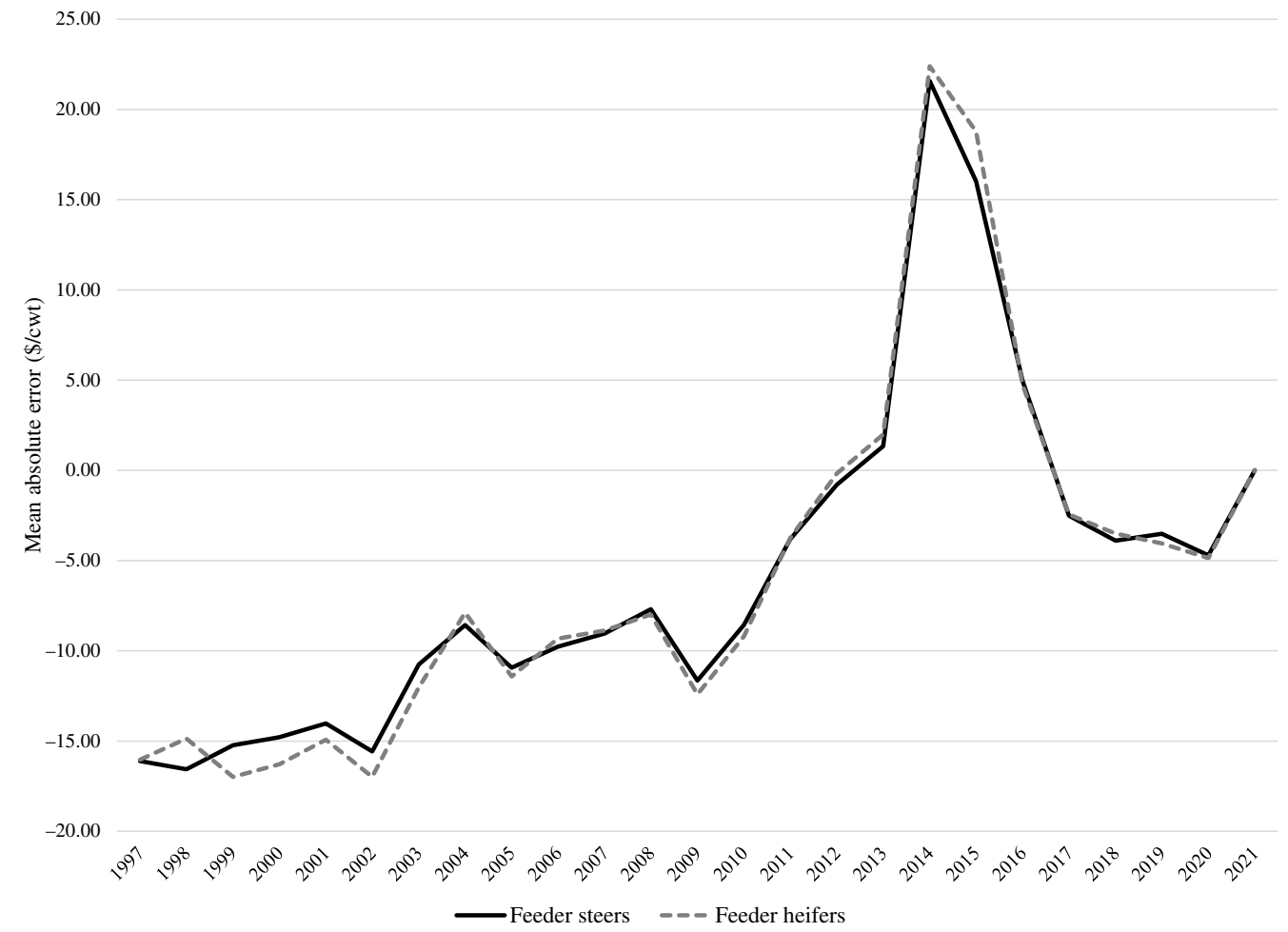

Figure 2. Feeder steer and heifer MAE model year coefficients (Base $=2021$ ).

experienced in 2011 by 2018, indicated by the magnitude and statistical significance of those coefficients. Steer and heifer MAE in 2021 was between $\$ 2.50$ and $\$ 5.00$ per hundredweight higher than levels experienced in 2017-2020.

Feeder steer and heifer models exhibited seasonality in MAE (Figure 3). Steer MAE was not statistically different (0.05 level) than the January base in February, but was economically and statistically lower in spring, summer, and early fall (declining to \$1.94 per hundredweight lower than the January base in September) and higher in December ( $\$ 0.84$ per hundredweight over January). Relative to January, heifer MAE was economically and statistically lower through September (falling as low as $\$ 1.85$ per hundredweight under the January base in September) and was higher in December ( $\$ 1.10$ per hundredweight over January).

All categorical weight variables were statistically significant $(0.05$ level $)$ for feeder steer and heifer MAE models. Variables for 450-549 pound (FIVE) cattle were higher than the default $750-849$ pound animal with coefficients of $\$ 2.26$ and $\$ 0.42$ per hundredweight for steers and heifers, respectively. The opposite sign was observed for 550-649 pound (SIX) categorical weight with the steer (heifer) model having a coefficient $\$ 1.05(\$ 1.40)$ per hundredweight lower than the default 750-849 pound animal. Coefficients were also negative for 650-749 pound (SEVEN) categorical weight with the steer (heifer) model having $\$ 1.55$ (\$1.42) lower MAEs on average relative to $750-849$ pound cattle.

\section{Conclusions}

Basis predictability is essential for hedgers using the feeder cattle futures contract as a price risk management tool. Unexpected variation in basis adversely affects feeder cattle futures hedging 
1.50

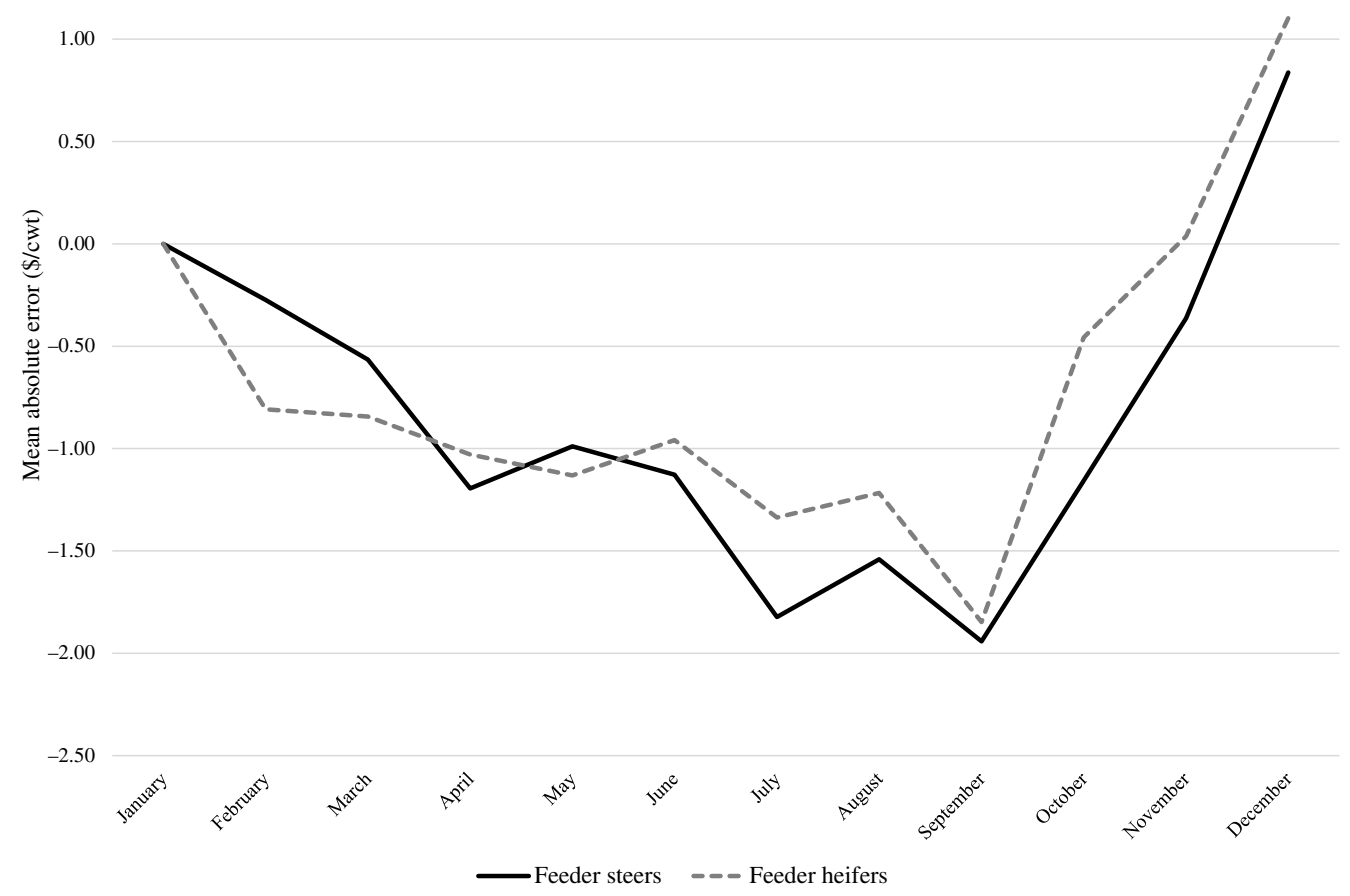

Figure 3. Feeder steer and heifer MAE model month coefficients (Base = January).

performance. Historic cattle price movements in 2014-2015 led to industry concerns over undue basis risk and the effectiveness of livestock futures contracts as hedging instruments. This study analyzed feeder cattle basis risk, implementing a comprehensive set of weekly auction data. We quantified market factors and feeder cattle characteristics associated with basis risk.

Monthly average feeder cattle and corn futures prices had little economic impact on feeder steer and heifer basis risk suggesting market price levels are not important basis risk determinants. Likewise, corn option market volatility had negligible influence on feeder cattle basis risk. Feed cost uncertainty is likely simultaneously priced into feeder cash and futures markets, thus not materially affecting basis risk.

Feeder cattle futures price volatility strongly impacts basis risk. This might help explain why concerns about the ability of feeder cattle futures to effectively manage price risk have been voiced during times of elevated futures price volatility. Cash prices may not immediately fully adjust to feeder futures price movements at times and/or futures market price limits prevent futures from changing as rapidly at times as the cash market. Whether futures contract specifications, alterations to specifications, or trade activity are driving feeder cattle basis variation is left for future research.

Feeder cattle basis risk varied geographically with steer basis risk generally higher relative to Oklahoma City in the rest of the 12-State Region and lower in eastern markets and heifer basis risk generally being similar in the western and southern portions of the 12-State Region but higher in northern and southeastern markets. Varying cattle characteristics across the country highlight the need for market participants to understand their unique local market conditions. Basis and basis risk analyses using disaggregated data provide more effective risk management strategies in a heterogeneous feeder cattle market. 
Seasonality was also present in feeder cattle basis risk, being lower in the spring, summer, and early fall and higher in early winter. Hedging effectiveness and basis-adjusted pricing mechanisms vary substantially throughout the year, having important implications for seasonal adjustments to risk management.

Light-weight feeder cattle (450-549 pounds) exhibited greater basis risk than cattle closer to futures contract weight specifications even after adjusting for differing hedge ratios (see Bina, Schroeder, and Tonsor [2021] for detailed analysis of feeder cattle hedge ratios). This was expected as cash prices of lighter-weight animals can diverge from prices of heavier animals specified in the feeder futures contract and, as such, would have higher basis risk. However, cattle weighing 550-749 pounds experienced lower basis risk on average relative to those weighing 750-849 pounds. This result was surprising as we expected basis risk to be similar or higher for these lighter-weight categories. We have no explanation for this occurrence but note that feeder steer basis risk varied substantially across weight. Calf sales account for most 450-549 pound steer transactions, while transactions of 650-749 pound steers are from either calf sales or from cattle leaving backgrounding operations. Impacts of weight on basis risk may depend on longer-term cattle cycle stages and/or changing drought conditions. We leave testing this for future research.

Basis risk has changed over time (even after adjusting for variation in feeder futures market prices and other cofactors), gradually increasing since 1997. During 2011-2013, feeder cattle basis risk increased notably as widespread drought conditions in major cow-calf regions persisted. Basis risk rose to historically high levels in 2014-2015, corresponding with extreme price movements in the cattle markets. However, addressing industry concerns (e.g., National Cattlemen's Beef Association, 2016; Peel, 2020), economically significant declines in basis risk post-2015 indicates feeder cattle basis risk returned to levels similar to 2011 by 2018. Though basis risk was historically high in 2014-2015 and questions regarding undue basis variability arose, this likely resulted from overall cattle market disequilibrium as prices were rapidly adjusting to evolving market information. Whether feeder futures contract specifications could have been modified to improve basis risk during that unprecedented time period is unclear, though we hypothesize daily price limits may have at times precluded futures and cash prices from keeping aligned, a topic for future research. Viability of the feeder cattle contract as a risk management tool remains similar to pre-2014, though continued assessment and discussion between industry users and contract designers is recommended to ensure successful future performance.

Author Contributions. Conceptualization, G.T.T. and T.C.S.; Data Curation, J.D.B.; Formal Analysis, J.D.B.; Methodology, J.D.B, G.T.T. and T.C.S.; Supervision, T.C.S.; Visualization, J.D.B.; Writing-Original Draft, J.D.B., G.T.T., and T.C.S.; Writing-Review \& Editing, J.D.B., G.T.T., and T.C.S.

Competing Interests. Bina, Schroeder, and Tonsor declare none.

Data Availability Statement. Feeder cattle auction data that supports the findings of this study are available from the United States Department of Agriculture Agricultural Marketing Service (USDA AMS). Restrictions apply to the availability of this data, which were used under license for this study. Data are available from the authors with the permission of USDA AMS. Futures market data that supports the findings of this study are available through Bloomberg L.P.

Funding Statement. This research received no specific grant from any funding agency, commercial, or not-for-profit sectors.

\section{References}

Bina, J.D., and Schroeder, T.C. “Overview of the CME Group Feeder Cattle Futures Contract”. 2019. Internet site: https:// agmanager.info/livestock-meat/marketing-extension-bulletins/marketing-strategies-and-livestock-pricing/overview-cme (Accessed October 5, 2020).

Bina, J.D., Schroeder, T.C., and Tonsor, G.T. "Conditional Feeder Cattle Hedge Ratios: Cross Hedging with Fluctuating Corn Prices.” Journal of Commodity Markets (2021). In Press. doi.org/10.1016/j.jcomm.2021.100193. 
Bloomberg L.P. Corn and feeder cattle futures settlement prices 01/01/1992 to 12/07/2021. 2020a. Retrieved December 7, 2021 from Bloomberg terminal.

Bloomberg L.P. Corn option implied volatilities 01/01/1997 to 12/07/2021. 2020b. Retrieved December 7, 2021 from Bloomberg terminal.

Canina, L., and Figlewski, S. “The Informational Content of Implied Volatility." The Review of Financial Studies 6,3(1993): 659-81. doi: 10.1093/rfs/5.3.659.

Coffey, B.K., Tonsor, G.T., and Schroeder, T.C. "Impacts of Changes in Market Fundamentals and Price Momentum on Hedging Live Cattle." Journal of Agricultural and Resource Economics 43,1(2018): 18-33. doi: 10.22004/ag.econ.267607.

Dhuyvetter, K.C., and Schroeder, T.C. "Price-Weight Relationships for Feeder Cattle." Canadian Journal of Agricultural Economics 48(2000): 299-310. doi: 10.1111/j.1744-7976.2000.tb00281.x.

Garcia, P., Leuthold, R.M., and Sarhan, M.E. "Basis Risk: Measurement and Analysis of Basis Fluctuations for Selected Livestock Markets.” American Journal of Agricultural Economics 66,4(1984): 499-504. doi: 10.2307/1240929.

Garcia, P., and Sanders, D.R. "Ex Ante Basis Risk in the Live Hog Futures Contract: Has Hedgers' Risk Increased?" The Journal of Futures Markets 16,4(1996): 421-40.

Kenyon, D., Bainbridge, B., and Ernst, R. "Impact of Cash Settlement on Feeder Cattle Basis." Western Journal of Agricultural Economics 16,1(1991): 93-105.

Koontz, S.R., Hudson, M.A., and Hughes, M.W. "Livestock Futures Markets and Rational Price Formation: Evidence for Live Cattle and Live Hogs." Southern Journal of Agricultural Economics 24,1(1992): 233-49. doi: 10.1017/S00813052 00026157.

Leuthold, R.M. "An Analysis of the Futures-Cash Price Basis for Live Beef Cattle." North Central Journal of Agricultural Economics 1,1(1979): 47-52. doi: 10.2307/1349316.

Leys, C., Ley, C., Klein, O., Bernard, P., and Licata, L. "Detecting Outliers: Do Not Use Standard Deviation Around the Mean, Use Absolute Deviation Around the Median." Journal of Experimental Social Psychology 49(2013): 764-66. doi: 10.1016/j.jesp.2013.03.013.

Liu, S., Brorsen, B.W., Oellermann, C.M., and Farris, P.L. "Forecasting the Nearby Basis of Live Cattle." The Journal of Futures Markets 14,3(1994): 259-73. doi: 10.1002/fut.3990140303.

Mitchell, J.L., Peel, D.S., and Brorsen, B.W. "Price Determinants of Bred Cows." Journal of Agricultural and Applied Economics 50,1(2018): 64-80. https://doi.org/10.1017/aae.2017.20.

National Cattlemen's Beef Association. "Letter to Terrence Duffy, Executive Chairman and President, CME Group.” 2016. Internet site: https://www.ncba.org/CMDocs/BeefUSA/Media/NCBAlettertoCMEreHFT.pdf (Accessed October 5, 2020).

Parcell, J.L., Schroeder, T.C., and Dhuyvetter, K.C. "Factors Affecting Live Cattle Basis." Journal of Agricultural and Applied Economics 32,3(2000): 531-41. doi: 10.1017/S1074070800020629.

Peel, D.S. "What's Worse Than No Feeder Cattle Futures?" 2020. Internet site: https://beefmarketcentral.com/story-whatsworse-feeder-cattle-futures-0-140746 (Accessed October 5, 2020).

Schroeder, T., Mintert, J., Brazle, F., and Grunewald, O. "Factors Affecting Feeder Cattle Price Differentials." Western Journal of Agricultural Economics 13,1(1988): 71-81. https://www.jstor.org/stable/40987944.

Schroeder, T.C., Tonsor, G.T., and Coffey, B.K. "Commodity Futures with Thinly Traded Cash Markets: The Case of Live Cattle.” Journal of Commodity Markets 15 (2019): 1-15. doi:.10.1016/j.jcomm.2018.09.005.

Seamon, F., Sullivan, J., and Umubyeyi, J. "Regional and Seasonal Differences in Feeder Cattle Basis." The Journal of the ASFMRA (2019): 121-25.

Tomek, W.G. "An Analysis of the Futures-Cash Price Basis for Live Beef Cattle: Comment." North Central Journal of Agricultural Economics 2,1(1980): 81-82. doi: 10.2307/1349274.

Tonsor, G.T., Dhuyvetter, K.C., and Mintert, J.R. "Improving Cattle Basis Forecasting." Journal of Agricultural and Resource Economics 29,2(2004): 228-41. doi: 10.22004/ag.econ.31115.

(U.S. Department of Agriculture Agricultural Marketing Service, unpublished data)

Zimmerman, L.C., Schroeder, T.C., Dhuyvetter, K.C., Olson, K.C., Stokka, G.L., Seeger, J.T., and Grotelueschen, D.M. "The Effect of Value-Added Management on Calf Prices at Superior Livestock Auction Video Markets." Journal of Agricultural and Resource Economics 37,1(2012): 128-43. https://www.jstor.org/stable/23243053. 
Table A1. Summary of regression analysis for MAE of feeder cattle price predictions, 1997-2021

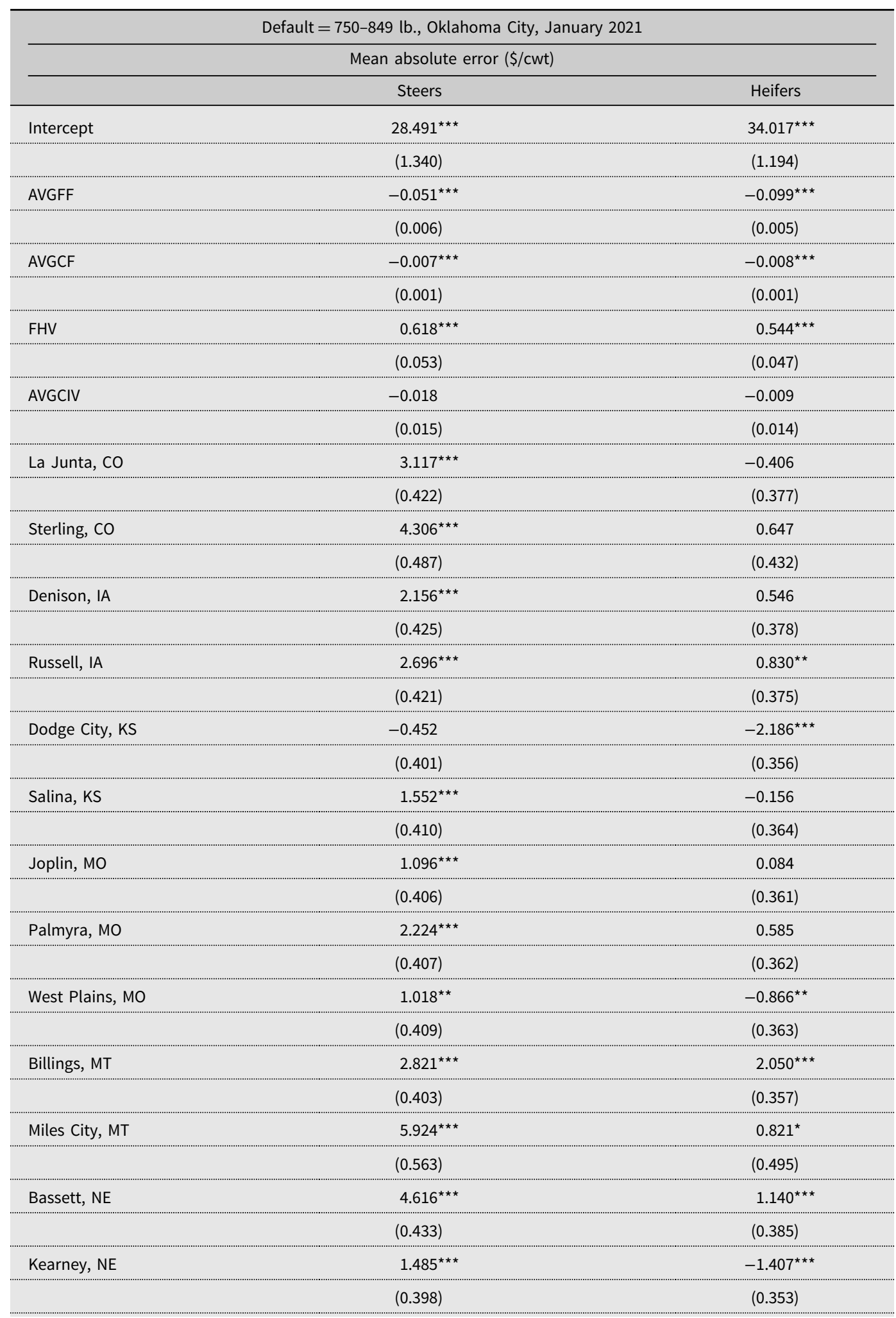


Table A1. (Continued)

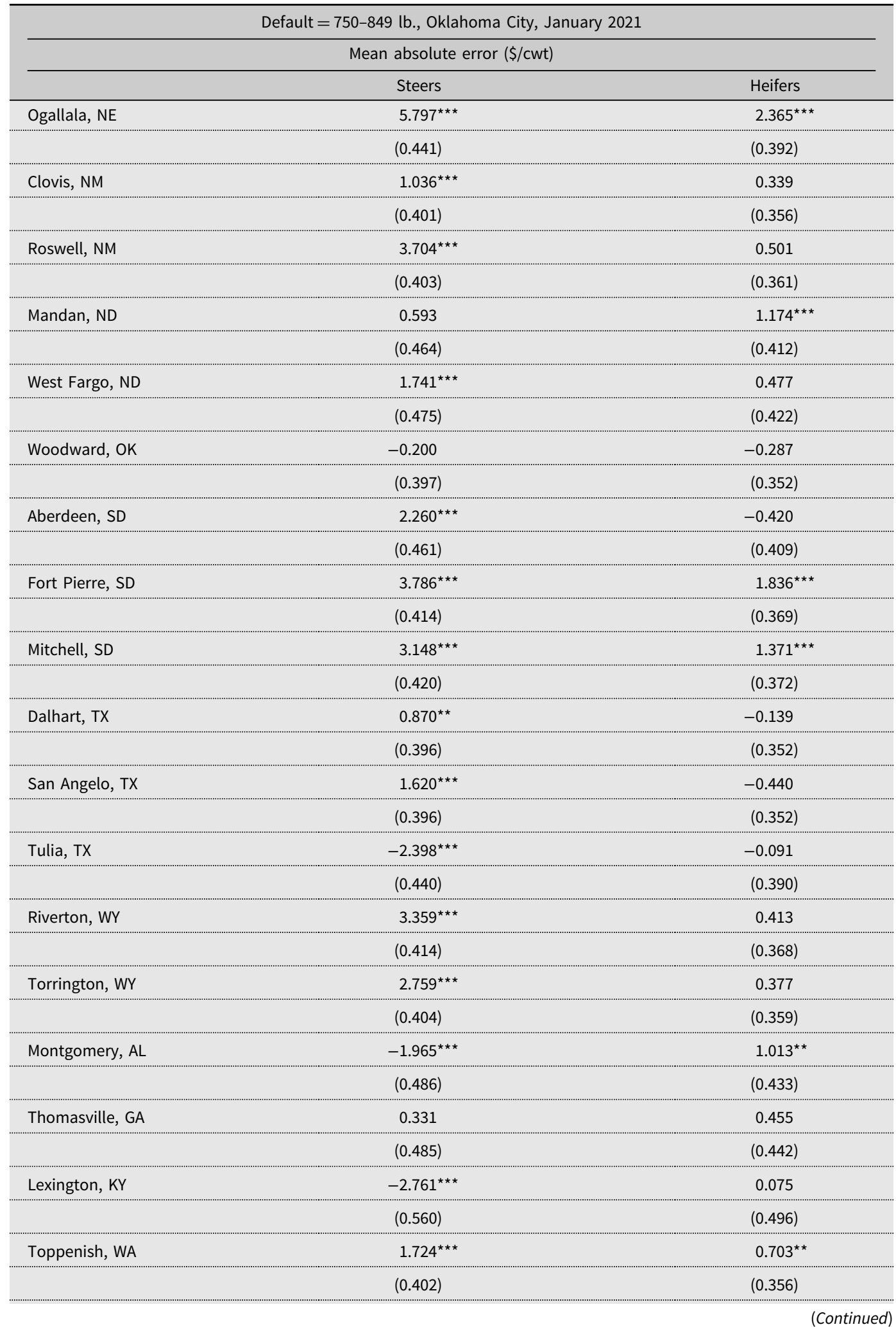


Table A1. (Continued)

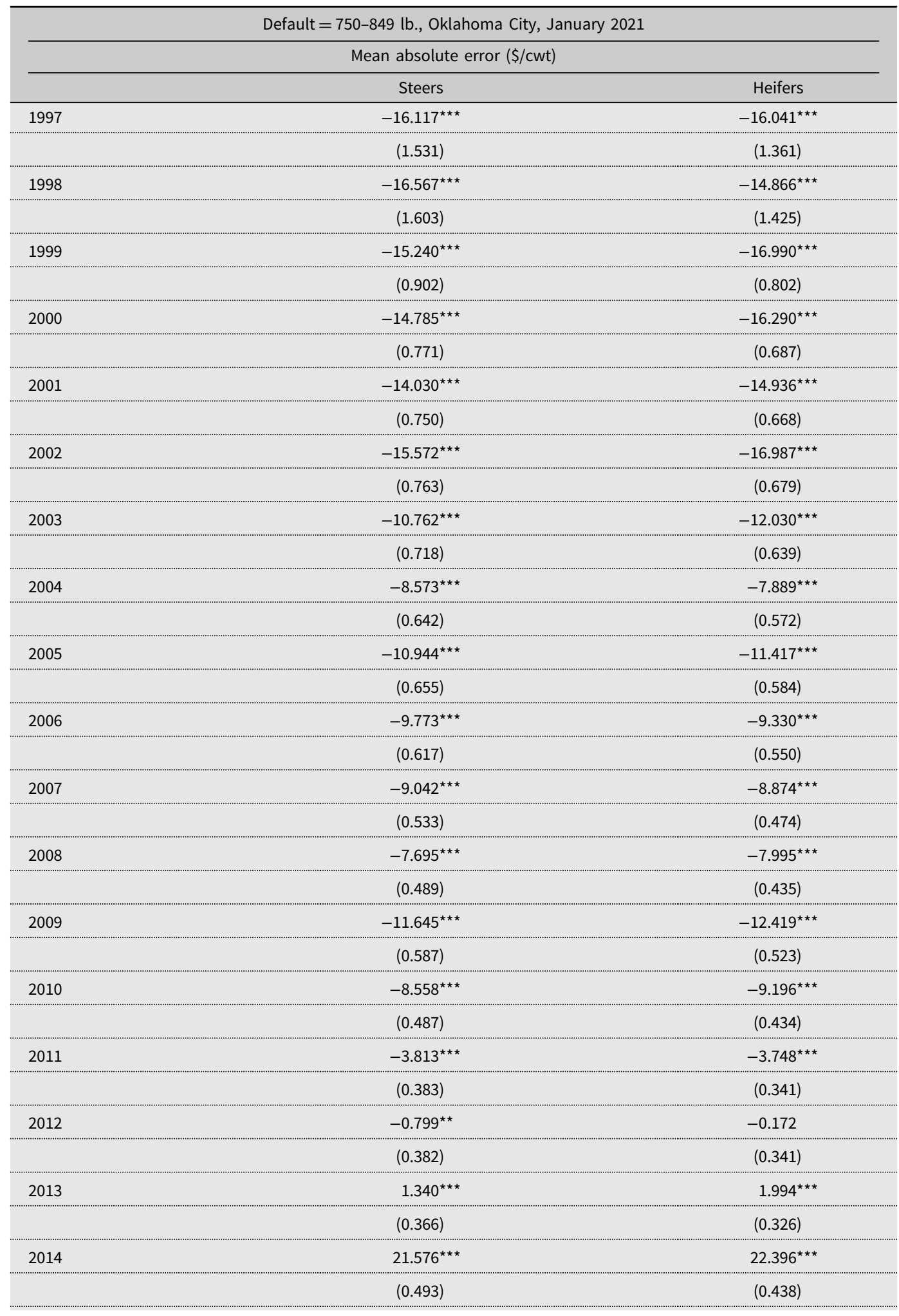


Table A1. (Continued)

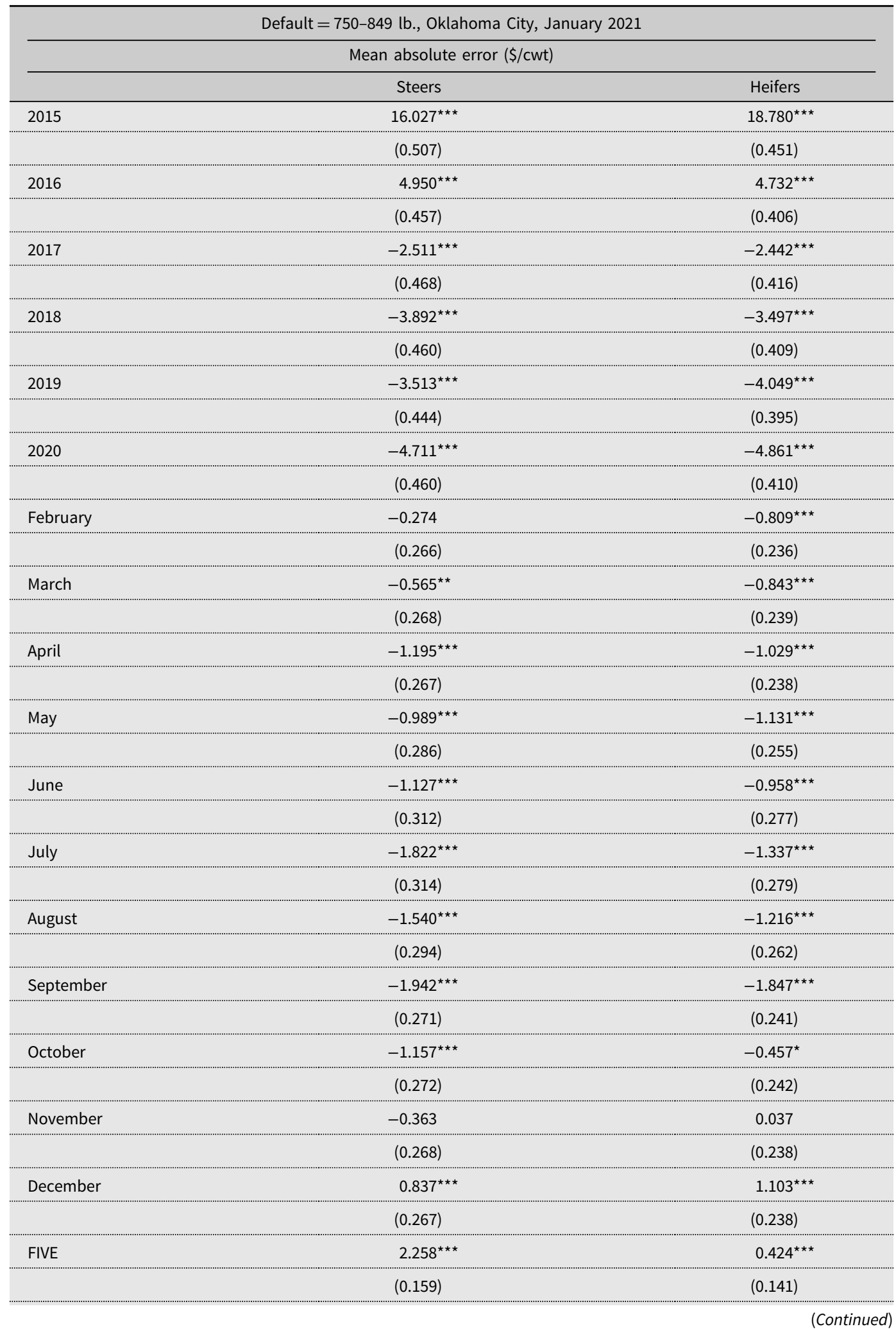


Table A1. (Continued)

\begin{tabular}{|c|c|c|}
\hline \multicolumn{3}{|c|}{ Default $=750-849$ lb., Oklahoma City, January 2021} \\
\hline \multicolumn{3}{|c|}{ Mean absolute error $(\$ / c w t)$} \\
\hline & Steers & Heifers \\
\hline \multirow[t]{2}{*}{ SIX } & $-1.048^{\star \star \star}$ & $-1.395^{\star \star \star}$ \\
\hline & $(0.158)$ & $(0.141)$ \\
\hline \multirow[t]{2}{*}{ SEVEN } & $-1.554^{\star \star \star}$ & $-1.415^{\star \star \star}$ \\
\hline & $(0.158)$ & $(0.141)$ \\
\hline Observations & 27,832 & 27,749 \\
\hline$R 2$ & 0.433 & 0.428 \\
\hline Adjusted $R 2$ & 0.432 & 0.427 \\
\hline Residual std. error & $9.299(\mathrm{df}=27,758)$ & $8.261(\mathrm{df}=27,675)$ \\
\hline F-statistic & $290.784^{\star \star \star}(\mathrm{df}=73 ; 27,758)$ & $284.036^{\star \star \star}(\mathrm{df}=73 ; 27,675)$ \\
\hline
\end{tabular}

Notes: Single, double, and triple asterisks $\left({ }^{*},{ }^{* \star},{ }^{* \star \star}\right)$ indicate statistical significance at the $10 \%, 5 \%$, and $1 \%$ level.

Values in parenthesis are standard errors of estimated coefficients.

Cite this article: Bina, J.D., T. C. Schroeder, and G. T. Tonsor (2022). "Feeder Cattle Basis Risk and Determinants." Journal of Agricultural and Applied Economics 54, 137-156. https://doi.org/10.1017/aae.2022.2 